\title{
PENGARUH KEGIATAN CAR FREE DAY (CFD) DI KOTA PEKANBARU UNTUK PENGURANGAN EMISI KARBON DARI KEGIATAN TRANSPORTASI
}

\author{
Aryo Sasmita \\ Teknik Lingkungan, Universitas Riau \\ Kampus Binawidya Km 12,5 Simpang Baru Panam, Pekanbaru 28293 \\ *E-mail: aryosasmita@gmail.com
}

\begin{abstract}
Abstrak
Adanya penurunan kualitas udara oleh emisi karbon yang dihasilkan dari kegiatan transportasi di Pekanbaru, secara tidak langsung dapat menyebabkan perubahan iklim. Jenis gas emisi yang utama dan di sektor transportasi sebagai akibat dari pembakaran bahan bakar adalah gas $\mathrm{CO}_{2}$ dan $\mathrm{CH}_{4}$. Penelitian ini dilakukan untuk mengetahui apakah kegiatan car free day (CFD) yang dilakukan oleh pemerintah Kota Pekanbaru setiap hari minggu pada puku 06:00 hingga pukul 09:00 WIB mampu memberikan dampak mengurangi emisi karbon yang dihasilkan dari kegiatan transportasi. Lokasi studi adalah jalan Diponegoro yang merupakan jalan yang dipergunakan untuk CFD. Pengumpulan data primer dilakukan pengaambilan perhitungan jumlah kendaraan dengan metode traffic counting. Kemudian dilakukan pengumpulan data sekunder, antara lain data perhitungan nilai emisi dengan mengumpulkan data perhitungan satuan mobil penumpang, faktor emisi untuk tiap jenis kendaraan dan data konsumsi energi spesifik untuk masing-masing kendaraan. Dari hasil perhitungan diketahui bahwa nilai emisi karbon dioksida yang berhasil dikurangi dengan adanya kegiatan CFD adalah 236,486 $\mathrm{kg} \mathrm{CO}_{2}$.
\end{abstract}

Kata kunci: mikroalga hijau, Sumber Nitrogen, ekstraksi, kandungan lipida/minyak

\begin{abstract}
Abstrak
A decrease in air quality by the carbon emissions resulting from transportation activities in Pekanbaru, can indirectly cause climate change. These gases are the primary and in the transport sector as a result of fuel combustion is $\mathrm{CO}_{2}$ and $\mathrm{CH}_{4}$. This study was conducted to determine whether the activities of car-free day (CFD) undertaken by the government of Pekanbaru every Sunday at Puku 06:00 until 09:00 am able to make an impact reducing carbon emissions resulting from transportation activities. The location study is Diponegoro street which is the road used for CFD. Primary data were collected we undertake the calculation of the number of vehicles with the traffic counting method. Then do the secondary data collection, including the data calculation of emissions by collecting data on passenger car unit calculations, emission factors for each vehicle type and energy consumption data specific to each vehicle. From the calculation it is known that the value of the carbon dioxide emissions were reduced by the activities of CFD is $236.486 \mathrm{~kg}$ of $\mathrm{CO}_{2}$.
\end{abstract}

Keywords: green microalgae, nitrogen source, extraction, content of lipid /oil 


\section{PENDAHULUAN}

Kota Pekanbaru sebagai salah satu kota besar di Indonesia dengan perkembangan perekonomian kota yang sangat pesat di segala bidang, baik dibidang industri, perdagangan maupun jasa. Kota Pekanbaru yang merupakan ibukota propinsi menjadi daya tarik bagi masyarakat, tidak hanya penduduk propinsi Riau, tapi juga penduduk dari provinsi lain disekitarnya. Ekonomi kota yang tumbuh telah mendorong peningkatan kebutuhan energi yang pada akhirnya menyebabkan bertambahnya buangan sisa aktivitas transportasi, industri, jasa, dan kegiatan lainnya ke udara. Transportasi merupakan salah satu kegiatan yang berkontribusi sebagai penghasil emisi karbon. Adanya penurunan kualitas udara oleh emisi karbon yang dihasilkan dari kegiatan transportasi di Pekanbaru, secara tidak langsung dapat menyebabkan perubahan iklim. Jenis gas emisi yang utama dan di sektor transportasi sebagai akibat dari pembakaran bahan bakar adalah gas $\mathrm{CO}_{2}$ dan $\mathrm{CH}_{4}$. Sektor transportasi juga menjadi penyumbang terbesar polusi udara, terutama pada daerah perkotaan yang menjadi pusat penggunaan kenderaan bermotor (Bappenas, 2013). Karbon dioksida $\left(\mathrm{CO}_{2}\right)$ merupakan gas rumah kaca yang mempunyai kontribusi besar terhadap pemanasan global dan perubahan iklim. Emisi karbondioksida tersebut merupakan komponen utama Gas Rumah Kaca (GRK) yang dapat memperbesar Efek Rumah Kaca (ERK). Efek rumah kaca ini dapat mengakibatkan terjadinya peningkatan suhu rata-rata permukaan bumi yang dikenal juga dengan pemanasan global. Oleh karena itu, diperlukan suatu perkiraan jumlah emisi karbon dioksida akibat pembakaran bahan bakar fosil (minyak bumi) atau yang lebih dikenal dengan carbon footprint. (Sasmita, 2011). Car free day di Pekanbaru pertama kali diadakan pada tanggal 6 Desember 2009, dan dilakukan setiap akhir pekan pukul 05:00 hingga 09:00 WIB. Car free day di Pekanbaru tidak menempati jalanan utama di kota ini, jalan Sudirman. ajang hari bebas kendaraan di minggu pagi Pekanbaru ini, dipusatkan di samping jalan utamanya, tepatnya di sepanjang jalan Diponegoro (anonim, 2014). Konsep car free day awalnya ber tujuan untuk pengurangan penggunaan kendaraan bermotor dan pengurangan polusi udara (Saputra, 2012). Dalam perkembangannya kegiatan ini mampu menghadirkan dampak positif antara lain jalanan yang lebih lengang dan nyaman karena tak ada kemacetan dan capaian yang paling membahagiakan adalah kondisi kualitas udara yang berangsur membaik. Dampak positif lain yang hadir dari penerapan CFD ini adalah animo masyarakat untuk berolahraga yang meningkat. Ruas-ruas jalan yang ditetapkan sebagai kawasan CFD hampir selalu dipenuhi masyarakat yang berolahraga. Mulai dari sekedar berjalan kaki, bersepeda bahkan tak jarang yang bermain sepak bola atau bulutangkis. Kondisi ini berdampak langsung kepada peningkatan kualitas kesehatan masyarakat. Penelitian ini menghasilkan kesimpulan apakah ada pengaruh kegiatan CFD yang dilakukan oleh pemerintah kota Pekanbaru setiap minggu selama tiga jam di ruas jalan diponegoro dalam mengurangi nilai emisi karbon dioksida yang dihasilkan dari sektor transpotasi perkotaan di Pekanbaru.

\section{METODE}

Metode yang dilakukan adalah menghitung emisi karbondioksida yang dihasilkan dari kegiatan transportasi, dengan cara traffic counting pada hari lain dengan jangka waktu yang sama dengan kegiatan CFD yaitu pukul 06:00 hingga 09:00. Traffic counting dilakukan pada hari selasa, karena hari selasa merupakan hari yang dianggap memiliki tingkat aktivitas transportasi yang tinggi. Nilai emisi yang didapat merupakan nilai emisi yang berhasil dikurangi akibat dari kegiatan CFD. Untuk mendapatkan nilai emisi tersebut maka perlu dilakukan tahapan penelitian yang dimulai dari studi pustaka, pengumpulan data primer dan data sekunder, pelaksanaan sampling Traffic Counting, perhitungan data yang dikumpulkan, analisa dari data yang telah dihitung, dan pembahasan data tersebut. Hingga akhirnya didapatkan kesimpulan yang akhirnya dapat menjawab tujuan penelitian ini. 


\section{Lokasi Studi}

Dalam penelitian digunakan lokasi jalan Diponegoro menjadi menjadi objek studi. Alasan dipilih jalan Diponegoro adalah karena di Kota Pekanbaru jalan yang digunakan untuk kegiatan CFD hanyalah Jalan Diponegoro dan Jalan Gajah Mada. Lebih dipilihnya Jalan Diponegoro dibanding Jalan Gajah Mada karena Jalan Diponegoro lebih panjang dan lebih ramai dilalui oleh masyarakat.

\section{Data Primer}

Data Primer yang diperlukan adalah data sampling traffic counting, yaitu banyaknya kendaraan yang melewati jalan yang dijadikan lokasi penelitian dalam kurun waktu tertentu. Data traffic counting membedakan kendaraan berdasarkan jenisnya yaitu kendaraan roda dua atau roda empat. Data kendaraan roda empat terbagi lagi untuk jenis kendaraan roda empat (mobil) berbahan bakar bensin atau solar, dan masih terbagi lagi untuk bis dan truk. Sampling dilakukan dengan menggunakan camera video untuk merekam keadaan jalan. Perekaman dilakukan dari mulai jam 05:00 hingga pukul 09:00 WIB. Setelah selesai perekaman, barulah dilakukan perhitungan jumlah kendaraan dengan melihat hasil rekaman. Perekaman dilakukan pada kedua sisi jalan Diponegoro untuk mengetahui jumlah total kendaraan yang melewati jalan Diponegoro. Kedua sisi itu disebut jalur menuju RSUD dan jalur dan menuju jalan Pattimura. Penggunaan camera video dirasa lebih baik dan lebih tepat daripada perhitungan langsung untuk mengurangi kesalahan saat perhitungan jumlah kendaraan. Traffic Counting ini dilakukan pada tanggal 3 september 2014. Dari hasil sampling tersebut dapatkan data yang digunakan sebagai landasan penelitian ini, yaitu jumlah kendaraan yang melewati jalan diponegoro yang dibedakan berdasarkan jenisnya.

\section{Data Sekunder}

Data sekunder diperoleh dari beberapa instansi atau penelitian sebelumnya dari yang terkait dengan penelitian ini antara lain:

Data faktor konversi jenis kendaraan ke satuan mobil penumpang(SMP) yang didapat dari data IPCC (intergovernmental panel on climate change).

Tabel 1. Konversi jenis kendaraan ke satuan mobil penumpang

\begin{tabular}{llr}
\hline NO & JENIS KENDARAAN & \multicolumn{1}{c}{ SMP } \\
\hline 1 & Kendaraan ringan & 1 \\
2 & Kendaraan berat & 1,20 \\
3 & Sepeda motor & 0,25 \\
\hline
\end{tabular}

(sumber : IPCC, 2006)

Faktor emisi kendaraan bermotor yang didapat dari jurnal internasional ataupun dari literatur buku seperti jurnal yang dikeluarkan oleh JICA 1996 dan jurnal-jurnal lainnya yang disesuaikan dengan kondisi di Indonesia.

Tabel 2. Faktor emisi tiap bahan bakar

\begin{tabular}{ll}
\hline \multicolumn{1}{c}{ Bahan Bakar } & Faktor Emisi \\
\hline Bensin & $2,6 \mathrm{~kg} \mathrm{CO}_{2} /$ liter \\
Solar & $2,2 \mathrm{~kg} \mathrm{CO}_{2} /$ liter \\
\hline
\end{tabular}

(Sumber : Bappenas, 2013)

Data konsumsi energi spesifik rata-rata tiap jenis kendaraan, yaitu data berapa liter yang diperlukan oleh suatu kendaraan untuk menempuh $100 \mathrm{~km}$.

Peta Kota Pekanbaru dan data klasifikasi jalan di Kota Pekanbaru untuk mengetahui kualifikasi jalan yang menjadi lokasi penelitian. Setelah data-data yang dibutuhkan terkumpul, dilakukan perhitungan nilai emisi yang dihasilkan oleh kegiatan transportasi di jalan Diponegoro pada hari normal dan membanding dengan hasil perhitungan tersebut dengan kondisi jalan Diponegoro ketika sedang menjalankan kegiatan CFD. 
Tabel 3. Konsumsi energi spesifik tiap jenis kendaraan

\begin{tabular}{llr}
\hline NO & JENIS KENDARAAN & $\begin{array}{c}\text { KONSUMSI } \\
\text { ENERGI SPESIFIK } \\
\text { (liter/100 km) }\end{array}$ \\
\hline 1. & Mobil Penumpang & 11,79 \\
& -Bensin & 11,36 \\
2. & -Diesel/solar & \\
& Bus Besar & 23,15 \\
& -Bensin & 16,89 \\
3. & -Diesel/solar & 13,04 \\
4. & Bus Sedang & \\
& -Bensin & 11,35 \\
& -Diesel/solar & 11,83 \\
5. & Bemo, Bajaj & 10,99 \\
6. & Taksi & 10,88 \\
& -Bensin & 6,25 \\
& -Diesel/solar & 15,82 \\
7. & Truk Besar & 15,15 \\
8. & Truk Sedang & 8,11 \\
9. & Truk Kecil & 10,64 \\
& -Bensin & 2,66 \\
\hline & -Diesel/solar & \\
10. & Sepeda Motor & \\
\hline
\end{tabular}

(Sumber : Jinca, 2009)

\section{HASIL DAN PEMBAHASAN}

\section{Sampling Traffic Counting}

Dari hasil sampling traffic counting yang dilakukan pada tanggal 3 september 2014, didapatkanlah data jumlah kendaraan yang melewati jalan Diponegoro pada waktu pengambilan sampling pukul 06:00 hingga
09:00 WIB total sebanyak 9574 kendaraan untuk jalur 1 dan 10888 untuk jalur 2. Kedua data tersebut digabungkan, untuk memudahkan perhitungan. Dengan rincian 2134 unit untuk kendaraan ringan, 307 unit untuk kendaraan berat dan 18021 unit untuk sepeda motor. Untuk lebih jelas data jumlah kendaraan tersebut, dapat dilihat dari Tabel 4.

Dari data traffic counting, kemudian dilakukan perhitungan dengan merubahnya menjadi satuan mobil penumpang. Hal ini dilakukan untuk memudahkan perhitungan. Cara perhitunga nilai smp adalah dengan mengkalikan jumlah kendaraan dengan faktor smp dari masingmasing jenis kendaraan. Data perhitungan SMP untuk masing masing jenis kendaraan dapat dilihat pada tabel 5 .

Dari hasil perhitungan diatas diketahui bahwa emisi yang dihasilkan di jalan diponegoro, saat pengambilan sampling dari kendaraan berbahan bakar bensin sebesar 118,622 Juta $\mathrm{Kg} \mathrm{CO}_{2}$ dan solar kendaraan berbahan bakar solar 117,864 $\mathrm{kg} \mathrm{CO}_{2}$. Dan jika ditotal maka emisi yang dihasilkan adalah sebesar 236,486 $\mathrm{kg} \mathrm{CO}_{2}$. Nilai ini lah yang menjadi emisi karbon dioksida yang berhasil dikurangi karena adanya kegiatan CFD. Besarnya nilai emisi karbon dioksida yang dapat dikurangi ini dikarenakan pagi hari adalah jam puncak aktivitas masyarakat yang melewati Jalan Diponegoro.

Tabel 4. Data Hasil Traffic Counting

\begin{tabular}{|c|c|c|c|c|c|c|c|c|}
\hline \multirow{2}{*}{ JAM } & \multicolumn{4}{|c|}{$\begin{array}{l}\text { KENDARAAN RINGAN } \\
\text { (Kendaraan/ } 3 \text { jam) }\end{array}$} & \multicolumn{2}{|c|}{$\begin{array}{c}\text { KENDARAAN } \\
\text { BERAT } \\
\text { (Kendaraan/ } 3 \text { jam) }\end{array}$} & \multicolumn{2}{|c|}{$\begin{array}{l}\text { SEPEDA MOTOR } \\
(\text { Kendaraan/ } 3 \text { jam })\end{array}$} \\
\hline & SEDAN & ANGKOT & PICKUP & $\begin{array}{r}\text { MINI } \\
\text { BUS }\end{array}$ & BIS & TRUK & $\begin{array}{l}\text { SEPEDA } \\
\text { MOTOR }\end{array}$ & $\begin{array}{l}\text { BECAK } \\
\text { MOTOR }\end{array}$ \\
\hline $6: 00-7: 00$ & 372 & 196 & 23 & 86 & 50 & 32 & 8.244 & 6 \\
\hline $7: 00-8: 00$ & 260 & 91 & 31 & 110 & 52 & 27 & 6.536 & 4 \\
\hline $8: 00-9: 00$ & 470 & 178 & 98 & 219 & 40 & 106 & 3.226 & 5 \\
\hline $\begin{array}{l}\text { Total } \\
\text { berdasarkan } \\
\text { jenis }\end{array}$ & \multicolumn{4}{|c|}{2.134} & \multicolumn{2}{|c|}{307} & \multicolumn{2}{|c|}{18.021} \\
\hline
\end{tabular}


Tabel 5. Nilai SMP untuk Tiap Jenis Kendaraan

\begin{tabular}{clrrr}
\hline NO & JENIS KENDARAAN & SMP & JUMLAH KENDARAAN & NILAI SMP \\
\hline 1 & Kendaraan ringan & 1 & 2.134 & 2134 \\
2 & Kendaraan berat & 1,2 & 307 & 368,4 \\
3 & Sepeda motor & 0,25 & 18.021 & $4.505,25$ \\
\hline
\end{tabular}

Tabel 6. Jumlah emisi yang dihasilkan

\begin{tabular}{|c|c|c|c|c|c|c|c|}
\hline \multirow[b]{2}{*}{ NO } & \multirow{2}{*}{$\begin{array}{c}\text { JENIS } \\
\text { KENDARAAN }\end{array}$} & \multicolumn{2}{|c|}{ NILAI SMP } & \multicolumn{2}{|c|}{ Faktor emisi } & \multirow{2}{*}{$\begin{array}{c}\text { Debit emisi } \\
\text { bensin } \\
\left(\mathrm{kg} \mathrm{CO}_{2}\right)\end{array}$} & \multirow{2}{*}{$\begin{array}{c}\text { Debit emisi } \\
\text { solar } \\
\left(\mathrm{kg} \mathrm{CO}_{2}\right)\end{array}$} \\
\hline & & BENSIN & SOLAR & $\begin{array}{l}\text { Bensin (kg } \\
\mathrm{CO}_{2} / \text { liter) }\end{array}$ & $\begin{array}{c}\text { Solar } \\
\left(\mathrm{kg} \mathrm{CO}_{2} / \text { liter }\right) \\
\end{array}$ & & \\
\hline 1 & Kendaraan ringan & $1.920,6$ & 213,40 & 2.600 & 2.200 & 4.993 .560 & 469.480 \\
\hline 2 & Kendaraan berat & 736,80 & 294,72 & 2.600 & 2.200 & 1.915 .680 & 648.384 \\
\hline 3 & Sepeda motor & $4.505,25$ & 0 & 2.600 & 2.200 & 11.713 .650 & 0 \\
\hline \multicolumn{6}{|c|}{ Total debit emisi untuk tiap jenis bahan bakar } & 18.622 .890 & 1.117 .864 \\
\hline
\end{tabular}

\section{KESIMPULAN}

Kesimpulan yang dapat ditarik dari penelitian ini adalah:

Dari hasil sampling traffic counting diketahui jumlah kendaraan yang melewati lokasi sampling dan pada waktu samping sebesar 18021 kendaraan yang terdiri dari kendaraan sedan, angkot, pick up, mini bus, bus, truk, dan sepeda motor. Besarnya emisi karbon yang dapat dikurangi dengan melakukan kegiatan CFD adalah sebesar 236,486 $\mathrm{kg} \mathrm{CO}_{2}$.

\section{Ucapan Terima Kasih}

Penulis mengucapkan terimakasih dan penghargaan yang sebesarnya kepada semua pihak yang telah membantu penyelesaian penelitian ini.

\section{DAFTAR PUSTAKA}

Bappenas. 2013. Pemantauan, evaluasi dan pelaporan pelaksanaan rad-grk. Jakarta:

Kementerian Perencanaan Pembangunan Nasional.
IPCC. 2006. Guidelines for National Green House Gas Inventories. Chapter 3: Mobile Combustion.

Jinca m.y. dkk. 2009. Pencemaran Udara Karbon Monoksida dan Nitrogen Oksida Akibat Kendaraan Bermotor Pada Ruas Jalan Padat Lalu Lintas di Kota Makassar. Simposium xii fstpt. Universitas Kristen Petra Surabaya. 14 November 2009.

Saputra, Isro dan Ridwan Sutriadi. 2012. Analisis Car-Free Days Berdasarkan Persepsi Pengunjung Dalam Konteks Perubahan Perilaku Penggunaan Kendaraan Pribadi. Studi Kasus: Car Free-Days Jalan Ir. H.Juanda. Jurnal Perencanaan Wilayah dan Kota B SAPPK V3N2.

Sasmita, Aryo. 2011. Kajian Model Emisi Karbondioksida Dari Kegiatan Transportasi Di Kota Surabaya. Laporan Tesis. Program Magister Teknik Lingkungan. ITS-Surabaya. 